for teacher training colleges. In the West Midlands, however, the figures were only $48 \cdot 4$ and $47 \cdot 2$ per cent. Wales compares very favourably with England; 71 per thousand of the age group took up new awards at the universities and 63 per thousand at the colleges of education.

\section{HEALTH ADMINISTRATION}

\section{Befter Hospital Services}

\section{from our Social Medicine Correspondent}

BoLD recommendations for curbing the uncoordinated growth of scientific services within hospitals are spelt out in a report to the Health Ministers published last week (Hospital Scientific and Technical Services, HMSO, $7 s$ ). The report is based on the findings of a committee of eight which was appointed last year under the chairmanship of Sir Solly Zuckerman to consider the future organization and development of these services in National Health Service hospitals.

The principal proposal is that a Hospital Scientific Service should be set up in England and Wales, and Scotland, headed by National Hospital Scientific Councils which would advise on the organization and development of the service. Membership of the councils should include independent scientists, clinicians, medical administrators and medical and nonmedical members of the scientific service. At a lower level, it is proposed that Regional Hospital Boards should be responsible for planning the scientific services of the region, each board having a Regional Advisory Committee as well as a scientist, medical or nonmedical. It is also suggested that district hospital authorities should be responsible for the day-to-day management of hospital scientific services and that there should be a "division of scientific services" including such services as clinical biochemistry, computer science and statistics, haematology and blood transfusion.

The committee also recommends a new career structure similar to that in the Scientific Civil Service and the Medical Research Council. Although medical staff would usually remain, as at present, in the hospital medical staff structure, other scientific and technical staff would fall into the four main classes: scientific officer, technical officer, technical assistant and technical aide. The committee hopes that this career structure would broaden the basis of promotion, but it has nothing to say about rates of pay.

The committee's report is essentially a broad outline of the proposed hospital scientific service rather than a detailed plan. Nevertheless, it will undoubtedly give rise to much controversy, particularly among some sectors of the medical profession who may disapprove of the prospect of a versatile technician assisting in many disciplines rather than specializing in any particular one. Another foreseeable issue is the largescale employment of non-medical scientists in haematology, diagnostic X-ray departments and other specialties where they are not normally found. It has, however, become obvious that some drastic measures need to be taken if the shortage of hospital technicians is to be overcome and their dissatisfaction with the present service (which has probably done much to precipitate the committee's investigations) quelled. Equally important, it has become necessary to convince talented graduate non-medical scientists that as employees in the hospital service they will not merely be the handmaidens of the medics.

\section{PHOTOGRAPHY}

\section{Red Admiral Emergent}

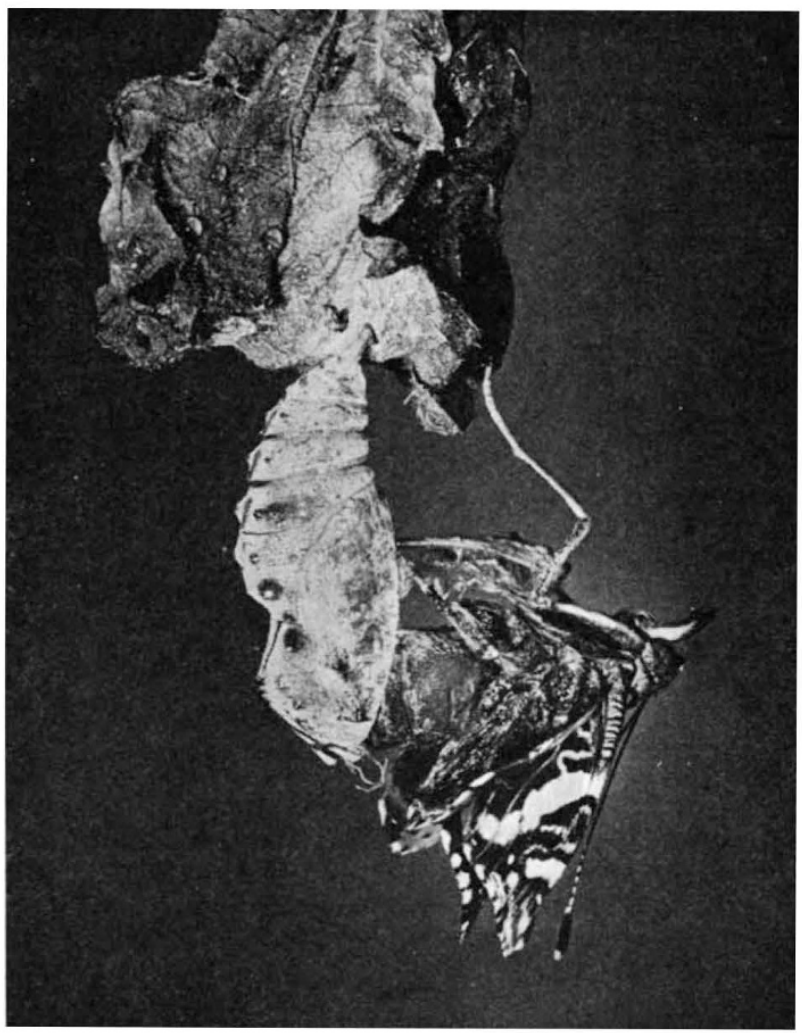

A Red Admiral struggling out of its chrysalis-a rare photograph taken by Mrs Jane Craik of Tavistock who has won the title of Wildlife Cameraman of 1968 in the competition organized jointly by the journal Wildlife and the Countryside and the Council for Nature. The prize for the best colour photograph went to $\mathrm{Mr}$ Jim Rowbottom of Fort William for his picture of a wild otter eating a fish on the foreshore in Argyli.

\section{FUEL POLICY \\ More Fuel to the Flames}

For some time, energy and fuel policy has looked the area of the national economy most likely to be amenable to numerical analysis and planning. The interest of the Ministry of Power in computer models, and the publication this week of an important mathematical analysis of the British fuel economy, tend to confirm this impression. The analysis comes from the Department of Applied Economics at Cambridge (The Demand for Fuel 1948-1975; a Sub-model for the British Fuel Economy; Chapman and Hall, $30 \mathrm{~s}$ ) and is principally the work of Kenneth Wigley, with assistance from other members of the department.

The analysis sets out to do two things: first, it makes a survey of the demand for different forms of fuel in Britain since 1948, and attempts to describe the trends in demand in the form of equations; secondly, it uses these equations to project demand forward to 